\title{
Modeling Wheat Yield and Weather Variability using Classification and Regression Tree Approach in Samastipur District of Bihar, India
}

\author{
Nidhi, S.P. Singh* and Subhash Kumar \\ Department of SMCA, FBSH, Dr. Rajendra Prasad Central Agriculture University, \\ Pusa (Samstipur), Bihar, India \\ *Corresponding author
}

\section{Keywords}

Wheat yield variability, Climate change, Crop growth stages; CART analysis

Article Info

Accepted:

15 July 2018

Available Online:

10 August 2018

\section{A B S T R A C T}

Climate change continues to have major impact on crop productivity all over the world. Researchers have evaluated the possible impact of global warming on crop yields. Predicting the potential effects of climate change on crop yields requires a model of crops respond to weather. Techniques commonly used for wheat yield estimation employ weather data over the growing season. Improved understanding of the potential effects of climate change on crop yields enables to plan for appropriate and timely responses. This study is to investigate how climate variability affects wheat yield at its different growth stages. Classification and regression tree (CART) analytical approach has been used to identify the relative importance of various weather parameters at different growth stages that are expected to affect the yield. Results from the CART models were able to explain 45 to $65 \%$ of the yield variability at different growth stages. Maximum temperature, relative humidity in morning and evaporation were found to be the important variables at most of the growth stages determining the yield variability. Increase in morning relative humidity during tillering, dough and maturity stages was observed to have a favorable impact on wheat yield. However an increase in maximum temperature above $24^{\circ} \mathrm{C}$ during the period of crown root initiation and ear head emergence led to decline in yield. CART proved a useful tool for arriving at less formal statistical inference that is expected to be comprehensible for the farmers as well.

\section{Introduction}

Climate change led increase in atmospheric temperature, carbon dioxide concentration and erratic precipitation has significantly impacted agricultural productivity. There has been marked increase in agricultural production as a consequence of continuous improvements in technology and crop varieties, but at the same time weather and climate still pose as the main uncontrollable factors affecting production
(Decker, 1994). The rising temperature in combination with a change in precipitation in some regions has affected crop yield. Lobell and Field (2007) reported a 0.6-8.9\% reduction in mean crop (wheat, rice, maize, barley soybean, sorghum) yield per $1^{\circ} \mathrm{C}$ rise in temperature at the global scale. A relative decline of about $17 \%$ in corn and soybean yield occurred per $1^{\circ} \mathrm{C}$ rise in the growingseason temperature in the USA from 1982 to 1998 (Lobell and Asner, 2003). Rice grain 
yield has declined by about $10 \%$ for every $1{ }^{\circ} \mathrm{C}$ enhancement in the growing-season minimum temperature in the Philippines from 1992 to 2003 (Peng et al., 2004).

The response of variation in crop yield to the climate varies widely among regions, depending on the cropping system, climate and spatial scale. Some studies find that temperature is more important and others find that rainfall is the most important factor. For example, the global analysis of Lobell and Field (2007) found a stronger effect of temperature, possibly because rainfall is not nearly as variable at global scales as it is on local scales. In a monsoon country such as India, rainfall is the key determinant of the productivity of rainfed crops. Challinor et al., (2003) showed that $50 \%$ of the variability in groundnut yield on the all-India scale could be explained by the variability in total seasonal rainfall from 1966 to 1995 . However the UK inter-annual climate variability can only account for about $10 \%$ of crop yield temporal variability (Landau et al., 1998).

Climate change impacts on India have farreaching consequences, as well; India is the world's second largest producer of agricultural outputs, and any change in production due to climate change leads to shift in global agricultural imports and exports. Agriculture being the most vulnerable sector to climate change, the productivity gets affected by a number of factors of climatic change including rainfall pattern, temperature, relative humidity, evaporation, changes in sowing and harvesting dates, water availability, evapotranspiration and land suitability. Mall and Singh (2000) observed that small changes in the growing season temperature over the years appeared as key aspect of weather affecting yearly wheat yield fluctuations. Pathak et al., (2003) concluded that the negative trends in solar radiation and an increase in minimum temperature resulted in declining trends of potential yields of wheat in the Indo-Gangetic plains of India. Selvaraju (2003) analyzed the relationship between Indian Summer Monsoon Rainfall (SMR) and food grain production in India. He found that the inter-annual variations are closely related. However, the magnitude of change in food grain production is smaller than the rainfall. Recent trends of a decline or stagnation in the yield of rice-wheat cropping system in Indo- Gangetic plain and north western India have raised serious concern about the region's food supply (Aggarwal et al., 2000; Pathak et al., 2003). This trend clearly indicates the reduced factor of productivity in case of the rice-wheat cropping systems.

Crop growth, development, and grain yields are greatly influenced by climatic factors, including solar radiation, precipitation, and temperature. These factors are closely related and affect yield in different ways. Consequently, understanding the factors that determine crop yield is essential to forecasting regional crop production, improving crop management techniques, and adopting feasible strategies to deal with climate change (Qian et al., 2008; Yu et al., 2008). Numerous studies have attempted to quantify the crop-climate relationship through the application of statistical regression analysis over the entire and/or critical growing period (Nicholls, 1997; Lobell and Asner, 2003; Lobell et al., 2006, 2007). Nicholls (1997) attributed the increase in wheat yields in Australia to the decrease in frost frequency. Lobell and Asner (2003) reported significant relationships between growing season temperatures and corn and soybean yields based on county level data inthe United States. Li et al., (2010) reported the negative effects of precipitation and seasonal mean temperature on wheat yield in China at different spatial scales.

Climate affects crop growth and development differently over its various growth stages. 
Thus by taking in to account of the weather experienced by the crop at different growth stages till the time of harvest, it is possible to work out pre-harvest yield forecasting models. $\mathrm{Yu}$ et al., 2014 considered the climate effects at both vegetative and reproductive stages (before and after flowering date, respectively) on wheat yield and observed that precipitation during the vegetative stage was the dominant and beneficial factor for wheat yields while increasing maximum temperature had a negative influence. You et al., (2009) reported a $1^{\circ} \mathrm{C}$ increase in wheat growing season temperature reduces wheat yields by about 3$10 \%$. Rising temperature over the past two decades accounted for a $4.5 \%$ decline in wheat yields in China.

This study aims to contribute to assessing how changing pattern of weather variables have affected the yields of major crops in India, for a time period spanning over 1984-2014.

\section{Materials and Methods}

\section{Study area and data set}

The study was carried out for Samastipur district of Bihar in India with latitude and longitude as $25^{\circ} 51^{\prime} 47.48^{\prime \prime} \mathrm{N}$ and $85^{\circ} 46^{\prime} 48.04$ $0^{\prime \prime} \mathrm{E}$ respectively. This is situated in Agroclimatic zone I (Northern West) with traditional agricultural practice prevalent. It is situated at an elevation of about $52 \mathrm{~m}$ above mean sea level. The climate of the site is characterized by hot and humid summers and cold winters with an average rainfall of 1200 $\mathrm{mm}, 70$ percent $(941 \mathrm{~mm})$ of which occurs during July -September and average maximum temperature is $36.6^{\circ} \mathrm{C}$ and minimum temperature is $7.7^{\circ} \mathrm{C}$. Frequent droughts and floods are common in the region.

Data on wheat productivity in $\mathrm{t} \mathrm{ha}^{-1}$ was obtained from Dept. of Agricultural Economics, DRPCAU Pusa, Samastipur,
Bihar for a period of 1984-2014. The data on the climate variables viz., Maximum temperature $\left({ }^{\circ} \mathrm{C}\right)$, Minimum Temperature $\left({ }^{\circ} \mathrm{C}\right)$, Relative Humidity (morning) (\%), Relative Humidity (evening) (\%), Rainfall $(\mathrm{mm})$ and Evaporation $\left(\mathrm{mm} \mathrm{m}^{-2}\right)$ was obtained from the Agro-meteorology Unit, Dr. Rajendra Prasad Central Agricultural University, Pusa, Samastipur, Bihar. Wheat growing season has been divided into eight growth stages namely seedling emergence, tillering, crown root initiation, boot stage, ear head emergence, milk stage, dough and maturity.

\section{Statistical Methods}

\section{Exploratory analysis}

Summary statistics for each of the weather parameters at different growth stages were displayed with the help of box and whisker plot. Box and whisker plot is a type of graphical display used to summarize a set of data based on the five number summaries of data. The summary statistics used to create a box and whisker plot are the median, the lower and upper quartiles (25\% and $75 \%)$ and the minimum and maximum values. The variation in the distribution of weather parameters across different growth stages can be seen from the plot.

\section{Classification and regression tree analysis}

Classification and Regression tree (CART) (Breiman et al., 1984; De'ath and Fabricius, 2000) has been used to describe the relationships and interactions between wheat yield and meteorological parameters at eight crop growth stages. CART is a non-parametric modeling approach that can explain the responses of a dependent from a set of independent continuous or categorical variables. Zheng et al., (2009) compared CART model with the general linear model 
(GLM) and explained a greater amount of yield variability with the same number of independent variables with CART approach (Lobell et al., 2005; Park et al., 2005). It has been used for detecting patterns in diverse areas, such as, epidemiology (Marshall, 2001), marine ecology (Dzeroski and Drumm, 2003), agricultural land use (Etter et al., 2006) and ecosystem classification (Dolan and Parker, 2005). In agriculture, the CART approach has been mainly used for detecting temporal and spatial variability in crop yields (PerezQuezada et al., 2003). Ferraro et al., (2009) used the CART analytical approach to study the influence of several factors controlling sugarcane productivity in Argentina.

CART models recursively partition the data to find increasingly homogeneous subsets based on independent variable splitting criteria using variance minimizing algorithms. The dependent data are partitioned into a series of descending left and right child nodes derived from parent nodes (Breiman et al., 1984). Once the partitioning has ceased, the child nodes are designated as terminal nodes. This approach has an advantage of providing easily comprehensible decision strategies. In this study regression tree analysis has been used to identify the most important weather variables affecting yield at eight growth stages of wheat. All statistical analyses were performed by $\mathrm{R}$ including summary statistics and classification and regression tree (CART) analysis.

\section{Results and Discussion}

\section{Variability of weather parameters and wheat yield}

Summary statistics of all the variables used in the study are given in Table 1. Variability in temperature and relative humidity were quite low in comparison to other variables like rainfall and evaporation. Rainfall exhibited highest variability where coefficient of variation was observed to be $29.42 \%$. Wheat yield was also observed to vary to a modest extent over the study period. Table 2 summarizes the descriptive measures of weather variables used in the study for different growth stages of wheat. The range of variation in different weather parameters across eight growth stages of wheat crop has been presented with the help of box and whiskers plots in Figures 1-3. The numerals in subscripts represent the eight growth stages. The minimum temperature was observed to be more fluctuating at almost all the stages as compared to maximum temperature. Similarly the relative humidity in morning was observed to be more consistent than the relative humidity in evening at almost all the stages. However morning relative humidity at last two stages viz., dough and maturity stages exhibited more variation. Almost all the weather variables exhibited skewed distribution.

\section{Explaining wheat yield variability}

To determine contribution of weather parameters at different growth stages, separate regression trees were fitted for wheat yield against all-weather variables. The weather parameters were used as explanatory variables for the CART decision algorithm (Breiman et al., 1984). The idea was to identify the most important weather parameter at different stages that is expected to affect the final wheat yield. CART works by automatically searching through alternative predictor variable that maximizes the quality of the split (separation) of the target variable into two 'child nodes'. The optimal splitting rules are found for all levels of all potential predictor variables. Once a best spilt is found, CART repeats the search process recursively for each child node, thereby creating a tree structure. The trees consist of a number of intermediate, splitting nodes and a series of terminal nodes. The explanatory variables appear in the 
consecutive splitting nodes in a hierarchy of decreasing explanatory power. CART algorithm generates a threshold at differentiate nodes. Initially the CART analysis results in a very large tree which is pruned back to an optimal sized tree based on relative error rates (misclassification error) for minimizing its cost complexity. The pruning method on misclassification error within one standard deviation of the minimum relative error was used (Breiman et al., 1984). The observations were randomly separated into two data sets, one for training $(2 / 3$ of the original data set: the learn set) and the other for validation (1/3 of the original data set: the validation set). A standard cross validation procedure was applied for calculating misclassification error. 1-CVlearn gives the estimate of the "portion of variance explained by the model" (Roel et al., 2007). The regression tree model for wheat yield as a function of weather variables at different growth stages are shown in figures 4(a-h).

The results indicated that at the stage of seedling emergence, evaporation was the only splitting variable and thus the only important variable determining yield variability with the prediction accuracy of $65.3 \%$.Over the whole study period of 29 years, there were 12 years when the evaporation was more than $2.2 \mathrm{~mm}$ $\mathrm{m}^{-2}$ and average yield was $2.4 \mathrm{t} \mathrm{ha}^{-1}$. At tillering stage, relative humidity in morning appeared to play an important role in determining the variability in wheat yield and this single split explained $55 \%$ of the variability in the yield. Morning humidity more than $90 \%$ was observed in 13 years with $2.4 \mathrm{t} \mathrm{ha}^{-1}$ of average wheat yield as compared to the average of $1.8 \mathrm{t} \mathrm{ha}^{-1}$ with humidity less than $90 \%$. Maximum temperature was observed to be the most important variable at crown root initiation stage and a temperature more than or equal to $23^{\circ} \mathrm{C}$ was found detrimental for the yield. When the maximum temperature was less than $23^{\circ} \mathrm{C}(\mathrm{n}=17)$ the average wheat yield was $2.2 \mathrm{tha}^{-1}$ in contrast to $1.9 \mathrm{t} \mathrm{ha}^{-1}$ when maximum temperature was comparatively high. The optimum regression tree at boot stage had three terminal nodes. Evaporation was the primary splitting node where average yield was $2.5 \mathrm{t} \mathrm{ha}^{-1}$ when it was more than $1.4 \mathrm{~mm} \mathrm{~m}^{-2}$. At the second and last level in the hierarchy, the splitting criterion was morning relative humidity. The yields with both evaporation $\left(<1.4 \mathrm{~mm} \mathrm{~m}^{-2}\right)$ and morning humidity $(>91 \%)$ averaged at $2.1 \mathrm{t}$ $\mathrm{ha}^{-1}$.

When the ear head emergence starts taking place, the maximum temperature was the primary splitting node. When it is lower than $24^{\circ} \mathrm{C}$, the average yield was $2.5 \mathrm{t} \mathrm{ha}^{-1}$. Thus maximum temperature of more than or equal to $24^{\circ} \mathrm{C}$ along with evaporation more than 2 $\mathrm{mm} \mathrm{m}{ }^{-2}$ led to an average yield of $2.2 \mathrm{t} \mathrm{ha}^{-1}$. $50 \%$ of the total yield variability was explained with this model.

Evaporation was the primary splitting node at milk stage and its threshold value greater than $3.4 \mathrm{~mm} \mathrm{~m}^{-2}$ led to an average yield of $2.5 \mathrm{t}$ $\mathrm{ha}^{-1}$. Evening relative humidity was the second most important variable at this stage to determine the variability in yield. The average yield was $2.2 \mathrm{t} \mathrm{ha}^{-1}$ when evaporation was less than the threshold value and evening relative humidity was greater than $48 \%$. Morning relative humidity was the dominant variable responsible for explaining the $53 \%$ variability at dough stage and 55\% variability in yield at maturity stage. The morning relative humidity more than $79 \%$ led to higher average yield of $2.3 \mathrm{t} \mathrm{ha}^{-1}$. Table 3 summarizes the results of regression tree model in terms of identifying important variables contributing to variation in yield at different growth stages of wheat. The threshold values of the variables are also given. Relative humidity in morning is observed to play an important role at tillering stage and also the last two stages i.e., dough and maturity. 
Table.1 Description of weather variables used for this study

\begin{tabular}{|l|c|c|c|c|c|c|c|} 
& Yield & $\begin{array}{c}\text { Min. } \\
\text { Temp. }\end{array}$ & $\begin{array}{c}\text { Max. } \\
\text { Temp. }\end{array}$ & $\begin{array}{c}\text { RH } \\
(\text { morning) }\end{array}$ & $\begin{array}{c}\text { RH } \\
(\mathbf{e v e n i n g})\end{array}$ & $\begin{array}{c}\text { Rainfal } \\
\mathbf{l}\end{array}$ & Evaporation \\
\hline & $(\mathrm{t} / \mathrm{ha})$ & $\left({ }^{\circ} \mathrm{C}\right)$ & $\left({ }^{\circ} \mathrm{C}\right)$ & $(\%)$ & $(\%)$ & $(\mathrm{mm})$ & $\left(\mathrm{mm} / \mathrm{m}^{2}\right)$ \\
\hline Minimum & 0.84 & 14.7 & 29.6 & 78.3 & 48 & 508 & 2.1 \\
\hline Maximum & 3.80 & 20.9 & 31.7 & 91.5 & 59.6 & 2430 & 4.9 \\
\hline Mean & 2.09 & 19.43 & 30.71 & 85.25 & 54.75 & 1208.58 & 3.46 \\
\hline S.D. & 0.61 & 1.18 & 0.62 & 3.00 & 3.27 & 355.54 & 0.63 \\
\hline CV & 29.0 & 2.03 & 3.52 & 6.06 & 5.97 & 29.42 & 18.24
\end{tabular}

Table.2 Descriptive statistics of weather variable at different growth stages of wheat

\begin{tabular}{|c|c|c|c|c|c|c|}
\hline Growth Stage & Min Temp & Max Temp & RH(morning) & RH(evening) & Rainfall & Evaporation \\
\hline & $\left({ }^{\circ} \mathrm{C}\right)$ & $\left({ }^{\circ} \mathrm{C}\right)$ & $(\%)$ & $(\%)$ & $(\mathrm{mm})$ & $\left(\mathrm{mm} / \mathrm{m}^{2}\right)$ \\
\hline $\begin{array}{l}\text { Seedling } \\
\text { Emergence }\end{array}$ & $\begin{array}{c}14.03 \pm \\
1.94\end{array}$ & $\begin{array}{c}27.51 \pm \\
1.96\end{array}$ & $89.23 \pm 4.19$ & $50.41 \pm 9.67$ & $2.00 \pm 8.58$ & $2.32 \pm 1.73$ \\
\hline Tillering & $\begin{array}{c}11.73 \pm \\
1.48\end{array}$ & $\begin{array}{c}25.81 \pm \\
1.25\end{array}$ & $88.72 \pm 3.77$ & $46.86 \pm 7.89$ & $2.64 \pm 9.15$ & $2.00 \pm 0.99$ \\
\hline $\begin{array}{l}\text { Crown Root } \\
\text { Initiation }\end{array}$ & $9.42 \pm 1.33$ & $\begin{array}{c}21.74 \pm \\
4.37\end{array}$ & $89.45 \pm 2.91$ & $52.52 \pm 8.71$ & $4.77 \pm 7.69$ & $1.51 \pm 0.76$ \\
\hline Boot & $8.51 \pm 1.45$ & $\begin{array}{c}21.41 \pm \\
2.01\end{array}$ & $89.55 \pm 2.49$ & $55.46 \pm 7.27$ & $6.76 \pm 9.76$ & $1.47 \pm 1.51$ \\
\hline $\begin{array}{l}\text { Ear Head } \\
\text { Emergence }\end{array}$ & $\begin{array}{c}11.81 \pm \\
5.86\end{array}$ & $\begin{array}{c}24.47 \pm \\
2.44\end{array}$ & $88.14 \pm 3.70$ & $48.86 \pm 6.52$ & $\begin{array}{c}12.62 \pm \\
21.74\end{array}$ & $2.05 \pm 0.54$ \\
\hline Milking & $\begin{array}{c}12.54 \pm \\
1.57\end{array}$ & $\begin{array}{c}27.30 \pm \\
1.55\end{array}$ & $84.04 \pm 4.77$ & $44.06 \pm 8.33$ & $2.27 \pm 3.91$ & $2.73 \pm 0.82$ \\
\hline Dough & $\begin{array}{c}14.31 \pm \\
1.76\end{array}$ & $\begin{array}{c}29.93 \pm \\
1.84\end{array}$ & $82.37 \pm 6.63$ & $\begin{array}{c}40.91 \pm \\
10.30\end{array}$ & $2.02 \pm 4.78$ & $3.60 \pm 1.05$ \\
\hline Maturity & $\begin{array}{c}19.38 \pm \\
12.87\end{array}$ & $\begin{array}{c}32.39 \pm \\
2.40\end{array}$ & $78.94 \pm 7.32$ & $35.57 \pm 7.09$ & $1.87 \pm 3.76$ & $3.98 \pm 1.38$ \\
\hline
\end{tabular}

Table.3 Stage wise important variables affecting yield

\begin{tabular}{l|l|l|} 
Stages & Variables & Threshold Values \\
\hline Seedling Emergence & Evaporation & $>2.2 \mathrm{~mm} / \mathrm{m}^{2}$ \\
Tillering & RH (morning) & $>90 \%$ \\
Crown Root Initiation & Maximum Temperature & $<23^{\circ} \mathrm{C}$ \\
Boot & Evaporation, RH (morning) & $>1.4 \mathrm{~mm} / \mathrm{m}^{2},>91 \%$ \\
Ear head emergence & Maximum Temperature, Evaporation & $<24^{\circ} \mathrm{C},>2 \mathrm{~mm} / \mathrm{m}^{2}$ \\
Milk & Evaporation, RH (evening) & $>3.4 \mathrm{~mm} / \mathrm{m}^{2},>48 \%$ \\
Dough & RH (morning) & $>79 \%$ \\
Maturity & RH (morning) & $>79 \%$
\end{tabular}

Note: increased yield obtained at respective variables with $<$ or $>$ sign 
Fig.1 Range of variation of maximum and minimum across eight growth stages of wheat crop
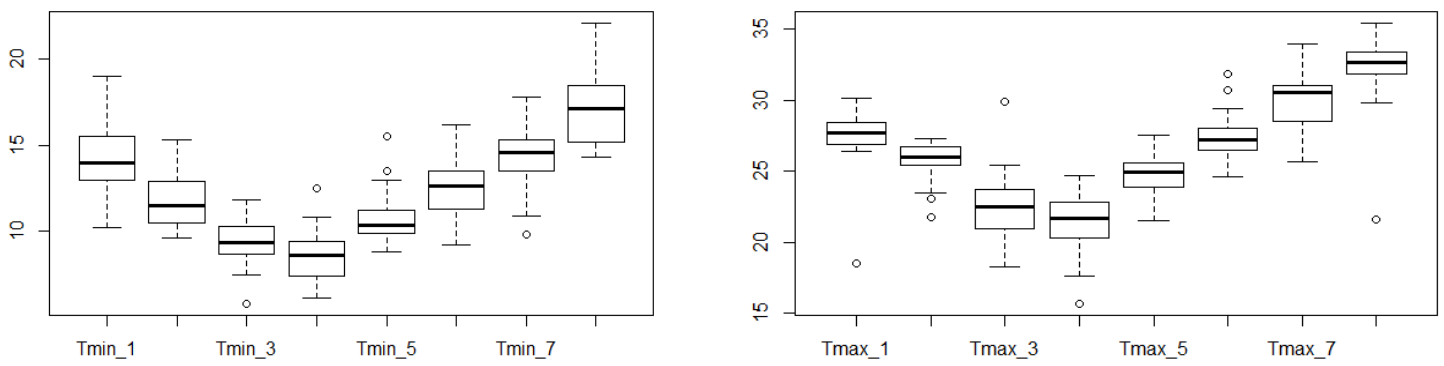

Fig.2 Range of variation of relative humidity (morning and evening) across eight Growth stages of wheat crop
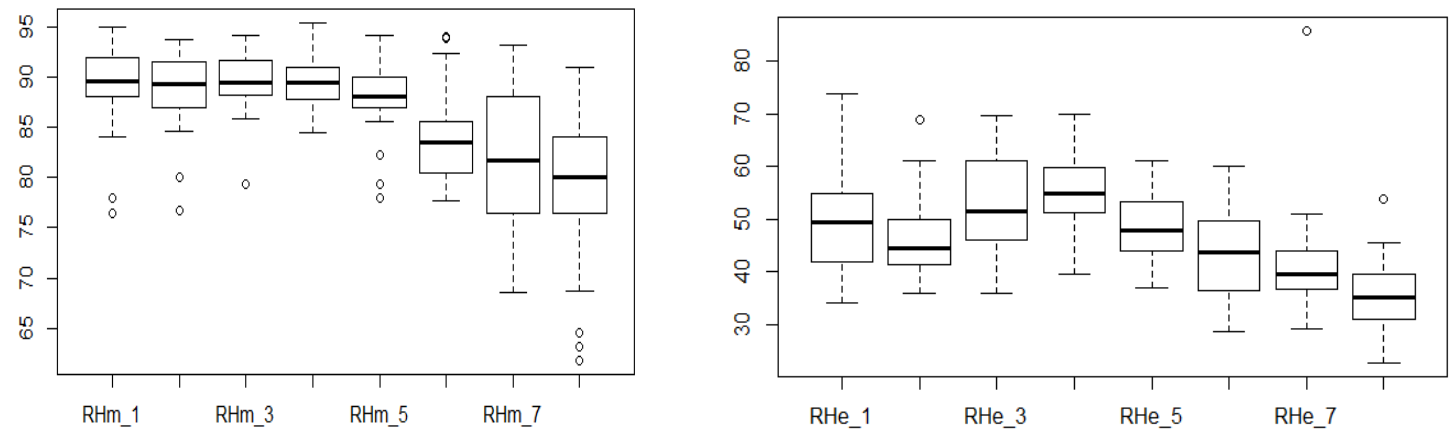

Fig.3 Range of variation of total rainfall and evaporation across eight Growth stages of wheat crop
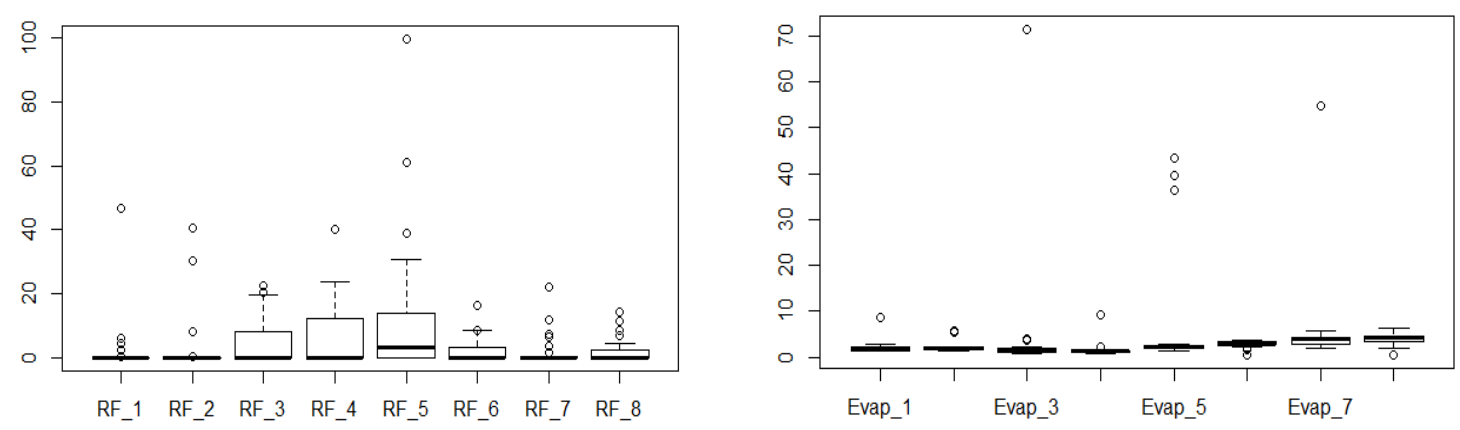
Fig.4 (a-h) Regression tree predicting wheat yields from weather parameters at eight growth stages. The model is read top down until terminal nodes appear

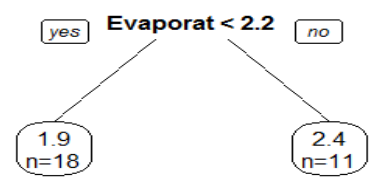

Figure 4(a)

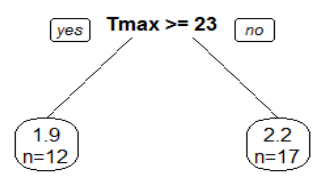

Figure 4(c)

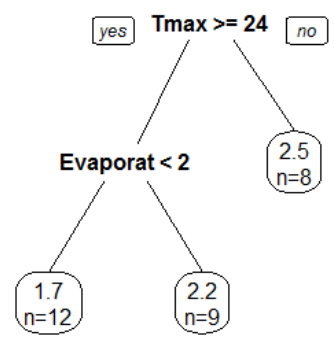

Figure 4(e)

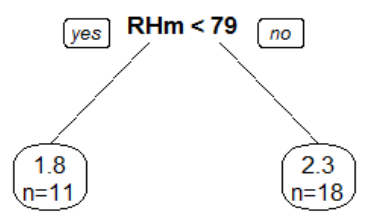

Figure $4(\mathrm{~g})$

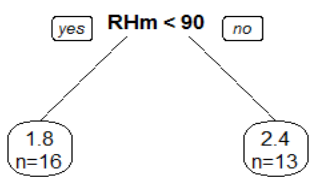

Figure 4(b)

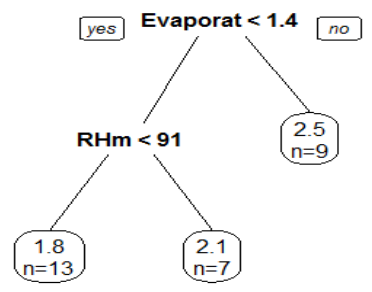

Figure 4(d)

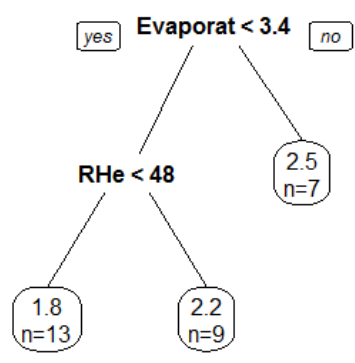

Figure 4(f)

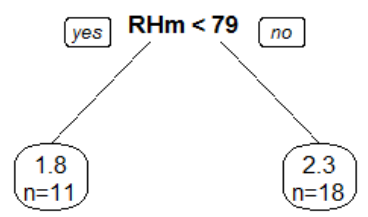


However, at tillering stage, morning humidity greater than $90 \%$ resulted in higher yield whereas at dough and maturity stage, it required to be more than $79 \%$ to get higher yield. Evaporation was observed to play a significant role at seedling emergence, boot and milking stage. Maximum temperature greater than $23-24^{\circ} \mathrm{C}$ at crown root initiation and ear head emergence stages was observed to have decline in average yield.

Several statistical methodologies have been used for examining the crop yield data. These include a range of techniques from simple linear regression to more complex non- linear models. There are circumstances when the statistical assumptions on which these models are based are violated due to inherent complexities in the data. The CART analysis applied here is a non- parametric technique that does not require the specification of any functional form. The present study attempted to stratify the yield variability into classes that reflect interactions between different weather parameters and thus may have practical utility for suitable interventions in accordance with the variation in weather and advice to farmers. Results from the CART models were able to explain 45 to $65 \%$ of the yield variability at different growth stages. The CART approach enabled to identify the threshold values of different weather variables at all the growth stages which can help to have an estimate of its impact on the final yield. Maximum temperature, relative humidity in morning and evaporation were found to be the important variables at most of the growth stages determining the yield variability. Increase in morning relative humidity during tillering, dough and maturity stages was observed to have a favorable impact on wheat yield. However an increase in maximum temperature above $24^{\circ} \mathrm{C}$ during the period of crown root initiation and ear head emergence led to decline in yield. This result is consistent with $\mathrm{Yu}$ et al., (2014).
Rainfall did not appear as the splitting criteria at any of the stage. The model can be further refined by taking into account more factors like soil properties and farm management practices. Crop growth performance is assumed to be the first visual indication of the final yield and hence inclusion of phenological characters in the model is also expected to enhance its prediction accuracy.

The yield variability owing to climate change induced aberrations in weather pose a problem to farmers. There have been numerous attempts to explore the functional relationship between weather and yield to devise suitable interventions to mitigate its detrimental impact. The present study attempted to assess this relationship with CART analysis which helps in generating decision rules based on the threshold values of the weather variables. It helped in identifying the relative importance of different weather variables at eight growth stages of wheat crop so that the farmers can assess beforehand how the weather is going to affect the final yield. The wheat yield variability was largely dependent on temperature and morning relative humidity across the stages. This model can further be fine-tuned with inclusion of more variables affecting yield to have a clear picture of their synergistic effects.

\section{References}

Aggarwal, P.K. 2000. Application of systems simulation for understanding and increasing yield potential of wheat and rice', Ph.D. Thesis, Wageningen University, Netherlands.

Breiman, L., Friedman, J.H., Olshen, R.A. and Stone, C.J. 1984. Classification and Regression Trees. Chapman and Hall (Wadsworth, Inc.), New York, US, pp. 254. 
Challinor, A.J., Slingo, J.M., Wheeler, T.R., Craufurd, P.Q, Grimes, D.I.F. 2003. Towards a combined seasonal weather and crop productivity forecasting system: determination of the working spatial scale. J. Appl. Meteorology 42: 175-192.

De'ath, G., Fabricius, K.E. 2000. Classification and regression trees: a powerful yet simple technique for ecological data analysis. Ecology 81: 3178-3192.

Decker, W.L. 1994. Developments in agricultural meteorology as a guide to its potential for the twenty-first century. Agric. Forest Meteorol. 69: 9-25.

Dolan, B.J. and Parker, G.R. 2005. Ecosystem classification in a flat, highly fragmented region of Indiana, U.S.A. Forest Ecol. Manag. 219: 109-131.

Dzeroski, S. and Drumm, D. 2003.Using regression trees to identify the habitat preference of the sea cucumber (Holothuria leucospilota) on Rarotonga, Cook Islands. Ecol. Model. 170: 219226.

Etter, A., McAlpine, C., Wilson, K., Phinn, S. and Possingham, H. 2006. Regional patterns of agricultural land use and deforestation in Colombia. Agric. Ecosyst. Environ. 114: 369-386.

Ferraro, D.O., Rivero, D.E. and Ghersa, C.M. (2009). An analysis of the factors that influence sugarcane yield in Northern Argentina using classification and regression trees. Fields Crop Res.112: 149-157

Landau, S., Mitchel, R.A.C., Barnett, V., Coll,s J.J., Craigon, J., Moore, K.L. and Payne, R.W. 1998. Testing winter wheat simulation models' predictions against observed UK grain yields. Agric. For. Meteorol.89: 85-99.

Li, S., Wheeler, T., Challinor, A., Lin, E., Ju, $\mathrm{H}$. and $\mathrm{Xu}, \mathrm{Y}$. 2010.The observed relationships between wheat and climate in China. Agric. For. Meteorol.150: 1412-1419.

Lobell, D.B. and Asner, G.P. 2003. Climate and management contributions to recent trends in U.S. agricultural yields. Science. 299: 1032.

Lobell, D.B., Cahill, K.N. and Field, C.B. 2007. Historical effects of temperature and precipitation on California crop yields. Clim. Change. 81: 187-203.

Lobell, D.B., Ortiz-Monasterio, J.I., Asner, G.P., Naylor, R.L. and Falcon, W.P. 2005.Combining field surveys, remote sensing, and regression trees to understand yield variations in an irrigated wheat landscape. Agron. J. 97: 241-249.

Mall, R.K. and Singh, K.K. 2000. Climate variability and wheat yield progress in Punjab using the CERES wheat and WTGROWS models. VayuMandal. 30(3-4): 35-41.

Marshall, R.J. 2001. The use of classification and regression trees in clinical epidemiology. J. Clin. Epidemiol.54: 603-609.

Nicholls, N. 1997. Increased Australian wheat yield due to recent climate trends.Nature 387, 484-485.

Park, S.J., Hwang, C.S., Vlek, P.L.G., 2005. Comparison of adaptive techniques to predict crop yield response under varying soil and land management conditions. Agric. Syst. 85: 59-81.

Pathak, H., Ladha, Aggarwal P.K., Peng, S., Das, S., Singh, Y., Singh, B., Kamra, S.K., Mishra, B., Sastri, A.S.R.A., Aggarwal, H.P., Das, D.K. and Gupta, R.K. 2003. Trends of climatic potential and on-farm yields of rice and wheat in the Indo-Gangetic plains. Field Crops Res. 80: 223-234.

Peng, S., Huang. J., Sheehy, J.E., Laza, R.C., Visperas, R.M. and Zhong, X. 2004. Rice yields decline with higher night 
temperature from global warming. Proc. Natl. Acad. Sci.101: 9971-9975.

Perez-Quezada, J.F., Pettygrove, G.S. and Plant, R.E. 2003.Spatial-temporal analysis of yield and soil factors in two four-crop-rotation fields in the Sacramento Valley. California Agron. J.95: 676-687.

Qian, B., Jong, R.D. and Gameda, S. 2008. Multivariate analysis of water related agroclimatic factors limiting spring wheat yields on the Canadian prairies. Euro.J. of Agron.30: 140-150.

Roel, A., Firpo, H. and Plant, R.E. 2007. Why do some farmers get higher yields? Multivariate analysis of a group of Uruguayan rice farmers. Comput. Electronics Agriculture. 58: 78-92.

Selvaraju, R. 2003. Impact of El NinoSouthern Oscillation on Indian food grain production. Int. J. Clim.23: 187206.

Tittonell, P., Shepherd, K.D., Vanlauwe, B. and Giller, K.E. 2008. Unravelling the effects of soil and crop management on maize productivity in smallholder agricultural systems of western Kenya
- An application of classification and regression tree analysis. Agric. Ecosys. Environ. 123: 137-150.

You, L., Rosegrant, M.W., Wood, S. and Sun, D. 2009. Impact of growing season temperature on wheat productivity in China. Agric. For. Meteorol. 149: 10091014.

Yu, Q., Li, L., Luo, Q., Eamus, D., Xu, S., Chen, C., Wang, E., Liu, J. and Nielsen, D.C. 2014. Year patterns of climate impact on wheat yields. Int. J. Clim. 34: 518-528.

Yu, Q., Wang, E.L. and Smith, C.J. 2008. A modeling investigation into the economic and environmental values of 'perfect' climate forecasts for wheat production under contrasting rainfall conditions. Int. J. Clim. 28: 255-266.

Zheng, H., Chen, L., Han, X., Zhao, X. and Ma, Y. 2009. Classification and regression tree (CART) for analysis of soybean yield variability among fields in Northeast China: The importance of phosphorus application rates under drought conditions. Agric. Ecosys. Environ. 132: 98-105.

\section{How to cite this article:}

Nidhi, S. P. Singh and Subhash Kumar. 2018. Modeling Wheat Yield and Weather Variability using Classification and Regression Tree Approach in Samastipur District of Bihar, India. Int.J.Curr.Microbiol.App.Sci. 7(08): 2517-2527. doi: https://doi.org/10.20546/ijcmas.2018.708.256 